


\title{
Study on the prevalence and risk factors of bovine tuberculosis in dairy cattle in Adama city, central Ethiopia
}

\author{
Tefera Woldemariam ${ }^{1}$, Samuel Bekele ${ }^{3}$, Gezahegne Mamo², Gobena Ameni ${ }^{3}$ \\ ${ }^{1}$ Faculty of Veterinary Medicine, Hawassa University, P.O.Box 05, Hawassa, Ethiopia \\ ${ }^{2}$ College of Veterinary Medicine, Addis Ababa University, P.O.Box 34, Bishoftu, Ethiopia \\ ${ }^{3}$ Aklilu Lemma Institute of Pathobiology, Addis Ababa University, P.O.Box 1176, Addis Ababa, \\ Ethiopia \\ *Corresponding author, email:teferailigo@gmail.com Tel (+251)911-660-467
}

\begin{abstract}
Bovine tuberculosis (bTB) is a serious infectious disease of cattle with significant economic impact and public health risk. It is particularly important in Ethiopia where effective control measures are lacking. This cross-sectional study was carried out between April and July 2016 on 1038 cattle selected from 206 dairy farms in Adama city located in central Ethiopia to estimate the prevalence of bTB and identify the potential risk factors using comparative intradermal tuberculin skin test. Accordingly, the individual animal level prevalence was found to be $2.1 \%$ (95\% CI: $1.35-3.22$ ). Of the 206 dairy farms included in the study, 7.3\% (95\% CI: $4.29-11.98$ ) had one or more 15 cattle positive for the tuberculin test. Furthermore, $5.5 \%$ of the examined cattle were found reactive for atypical Mycobacterium. Among the risk factors considered, age and lactation status of the animals were significantly associated $(p<0.05)$ with the prevalence of bTB. It was noted that the apparent prevalence of bTB positive reactivity was greater in young and non-lactating cattle than their counterparts. In conclusion, the present study revealed $2.1 \%$ prevalence of bTB in the dairy farms investigated and culling of positive reactors is recommended as a feasible control intervention.
\end{abstract}

Keywords: Adama; Bovine tuberculosis; CIDT; dairy cattle; Ethiopia

\section{Introduction}

Ethiopia has the largest cattle population in Africa which is estimated to be $60,392,019$ heads (CSA, 2018). The vast majority of the national herd is of 
indigenous zebu cattle maintained in rural areas under extensive husbandry systems. However, in response to the increasing demand for milk products and the Ethiopian government's efforts to improve productivity in the livestock sector, recent years have seen increased intensive husbandry settings holding exotic and cross breeds. This drive for increased productivity is however threatened by animal diseases that thrive under intensive settings, such as bTB (Firdessa et al., 2012).

Bovine tuberculosis (bTB) is a disease of zoonotic and economic importance caused predominantly by Mycobacterium bovis. The disease is transmitted between animals primarily by inhalation of aerosols although transmission through ingestion is also common in cattle grazing on pasture contaminated with $M$. bovis.The disease in cattle is characterized by the formation of granulomas in tissues and organs, more significantly in the lungs, lymph nodes, intestine, kidneys and others. The economic loss of bTB in dairy cattle include reduction in productivity, movement restrictions, screening costs, culling of affected animals, and trade restrictions (OIE, 2016).

Over the years several studies have been conducted in Ethiopia to show the importance of bTB. Published studies revealed that the prevalence of bTBin the country ranges from 2 to 47\% (Ameni et al., 2003; Ameni et al., 2007; Tschopp et al., 2010; Gumi et al., 2012; Firdessa et al., 2012; Nega et al., 2012; Mamo et al., 2013; Romha et al., 2014; Dejene et al., 2016). The studies have shown that bTB is an endemic disease in Ethiopian dairy farms due to lack of effective control programs and needs due attention. Although previous studies have indicated that the disease is endemic in the country, there is paucity of information about the status of bTB at Adama city where dairy farming with different levels of intensification is flourishing rapidly in response to a higher demand for milk and milk products. Therefore, this study was planned to estimate the current prevalence of bTB in the dairy farms of the town and identify the potential risk factors.

\section{Materials and Methods}

\section{Study area}

This study was conducted between April and July, 2016 in dairy herds found at Adama city, central Ethiopia. Adama is located at $8.54^{\circ} \mathrm{N}$ latitude and $39.27^{\circ} \mathrm{E}$ longitude and situated at an elevation of 1712 meters, $99 \mathrm{~km}$ southeast of Ad- 
dis Ababa. The city is situated along the road that connects Addis Ababa to Harar and Dire HYPERLINK "http://en.wikipedia.org/wiki/Dire_Dawa"Dawa. According to data obtained from Adama city Animal and Fisheries Department (ACAFD, 2016), there are about 10,000 dairy cattle in Adama and its suburbs. These animals are mainly cross-breed (Zebu X Holstein- Friesian) and kept under semi-intensive to intensive management system.

\section{Study design and sample size}

A cross sectional study design was followed throughout the course of the study. The sample size was determined according to Thrusfield (2005) considering $13.50 \%$ expected prevalence based previous report from cross and local breed animals from central Ethiopia (Ameni et al., 2007), 5\% absolute precision and $95 \%$ confidence level.

Adama town is divided into 14 kebeles (a kebele is the smallest administrative district in Ethiopia. In Adama, there are about 500 dairy farms. In the current study, 10-20 dairy farms were selected from each kebele considering the number of dairy farms existing in each kebele; willingness of the owners and availability of the road for transport during the study period. Accordingly, 206 farms were selected. Each selected farm has got 3-50 dairy cattle kept for milk production purpose mainly for family income. All cattle in the farm except sick and less than six months age have been tested. Most of dairy cattle were cross breeds and in each farm one local breed or no local breed was found, so breed differentiation was not reasonable. Based on above mentioned reasons a total of 1038 cattle were required for the study. These animals were obtained from 206 dairy farms found in the city. The sampling frame which represents the list of dairy farms in the city was constructed in collaboration with the veterinary department. All animals were included in farms with small herd size ( $\leq 10$ animals) in the study, while at least $10 \%$ were sampled from large farms (>10 animals). The study animals were identified by their ID numbers. During sampling, information about animal and herd- level factors, such as breed, age, body condition score, herd size, pregnancy status, stage of lactation, and parity was collected on especially designed format. Based on herd size, 185 (89.8\%) herds were small and only 21 (10.2\%) considered large. According to their lactation status the study animals were categorized as dry cows, lactating cows, and heifers and calves while in terms of parity they were classified in four categories (1-2, 3-5, $\geq 6$, and calf + heifer) (Vanholder et al., 2015). Body condition scoring (BCS) was made using a method developed for Zebu cattle 
(Nicholson and Butterworth, 1986). Accordingly, on the basis of observation of anatomical parts such as vertebral column, ribs, and spines, the study animals were classified as lean (1), medium (2) and good (3 \& 4). Age of the study animals was determined by using the dental eruption and wear as described by de Lahunta and Habel (1986). Accordingly, animals were categorized in three age groups: $<2,2-5$ and $\geq 6$ years. In all the farms, young animals under six months of age, cows in late gestation and those who had recently calved were not included in the study for fear of immune suppression that usually occurs in dairy cows starting from three weeks pre-calving to three weeks post calving (Radostits et al., 2001).

\section{Tuberculin skin testing}

Comparative intradermal tuberculin skin test (CIDT) was carried out by injecting both bovine purified protein derivative (PPD) and avian PPD (Prionics Lelystad B.V., The Netherlands). Two sites on the skin of the mid-neck of the cattle, $12 \mathrm{~cm}$ apart were shaved and skin thickness was measured with a caliper. One site was injected with an aliquot of $0.1 \mathrm{ml}$ of $3000 \mathrm{IU} / \mathrm{ml}$ bovine PPD into the dermis, and the other was similarly injected with $0.1 \mathrm{ml}$ of 2,500 IU/ml avian PPD. After 72 hrs., the skin thickness at the injection sites was measured and recorded. Results were interpreted according to the recommendations of the Office International des Epizooties (OIE, 2009) at $\geq 4 \mathrm{~mm}$ cut-off and also at $\geq 2 \mathrm{~mm}$ cut-off (Ameni et al., 2008). Thus, at cut-off $\geq 4 \mathrm{~mm}$, if the increase in skin thickness at the injection site for bovine PPD (PPD-B) was greater than the increase in skin thickness at the injection site for avian PPD (PPD-A) and PPD-B minus PPD-A was less than $2 \mathrm{~mm}$, between 2 and $4 \mathrm{~mm}$, or $4 \mathrm{~mm}$ and above, the animal was classified as negative, doubtful, or positive for BTB, respectively. At cut-off $\geq 2 \mathrm{~mm}$, if the difference between B and A was greater or equal to $2 \mathrm{~mm}$, the animal was considered as positive, while if the difference is less than $2 \mathrm{~mm}$, the animal was considered as negative. When the change in skin thickness was greater at PPD-A injection site, the animal was considered positive for mycobacterium species other than Mycobacterium tuberculosis complex. A herd was considered as positive if it had at least one tuberculin reactor animal.

\section{Data analysis}

All the data collected were coded and entered into Microsoft Excel Spreadsheet. All statistical analyses were performed on STATA version 11 (4905 
Lakeway Drive, College Station, Texas) using survey command. The apparent individual animal prevalence of bovine tuberculosis was calculated as the number of positive tuberculin reactors divided by the total number of cattle tested. Herd level prevalence was calculated as the number of herds with at least one-reactor positive animal divided by the total number of herds tested. Pearson chi- square was used to evaluate the statistical significance of the association between the independent variables (herd size, age, breed, BCS, pregnancy, parity and lactation) and dependent variable (tuberculin skin test result). Multivariable logistic regression analyses was performed to account for confounding effects and interaction between variables. P-value less than $5 \%$ was considered statistically significant.

\section{Results}

A total of 1038 cattle were screened for bTB and all animals were followed up for the second reading after 72 hours. Based on single CIDT result, the apparent individual animal prevalence of tuberculin reactors was $2.1 \%$ (95\% CI:1.35 - 3.22) using $2 \mathrm{~mm}$ cut-off point. Of the 206 herds tested, 15 (7.3\%, 95\% CI: 4.29 - 11.98) had one or more animals reactive to bovine PPD. The prevalence of $\mathrm{bTB}$ in individual herds ranges from $0-55.6 \%$.

Of the 206 herds tested, 15 (7.3\%, 95\% CI: 4.29 - 11.98) had one or more animals reactive to bovine PPD. The prevalence of bTB in individual herds ranges from $0-55.6 \%$ (Table 1).

On the other hand the change in skin thickness was found greater at avian PPD injection site than bovine PPD infection site in 5.5\% (57/1038) cattle showing that these animals are positive for Mycobacterium spp. other than $M$. tuberculosis complex (Table 1).

Table 1: Apparent prevalence of bovine and avian tuberculin reactors in Adama dairy farms, central Ethiopia

\begin{tabular}{lcccccccc}
\hline $\begin{array}{l}\text { Tuberculin } \\
\text { test type }\end{array}$ & $\begin{array}{l}\text { No. of } \\
\text { cattle } \\
\text { tested }\end{array}$ & $\begin{array}{l}\text { No. of } \\
\text { positive } \\
\text { reactors }\end{array}$ & $\begin{array}{l}\text { Preva } \\
\text { lence } \\
(\%)\end{array}$ & $\begin{array}{l}\text { No of } \\
\text { farm } \\
\text { tested }\end{array}$ & $\begin{array}{l}\text { No of } \\
\text { positive } \\
(\%)\end{array}$ & $\begin{array}{l}\text { 95\% } \\
\text { Confi } \\
\text { dence } \\
\text { Interval }\end{array}$ & X $^{\mathbf{2}}$ & P \\
\hline Bovine PPD & 1038 & 22 & 2.1 & 206 & $15(7.3)$ & $1.35-3.22$ & \\
Avian PPD & 1038 & 57 & 5.5 & 206 & $39(18.9)$ & $4.32-7.22$ & 17.2 & $<0.001$ \\
\hline
\end{tabular}


In univariable analysis of the potential risk factors, age of the animals was the only variable significantly contributed to positive reactivity to bTB $(\mathrm{P}<0.05)$ (Table 2).

Table 2: Univariable analysis of risk factors for bovine tuberculin reactors in Adama dairy farms using $\mathrm{X}^{2}$-test

\begin{tabular}{|c|c|c|c|c|c|c|}
\hline Variables & Category & $\begin{array}{l}\text { No of cattle } \\
\text { examined }\end{array}$ & $\begin{array}{l}\text { No of } \\
\text { positive }\end{array}$ & $\begin{array}{l}\text { Prevalence } \\
\text { (\%) }\end{array}$ & $x^{2}$ & p-value \\
\hline \multirow[t]{3}{*}{ Herd size } & & & & & 2.5 & 0.116 \\
\hline & Small $(<10)$ & 741 & 19 & 2.6 & & \\
\hline & Large $(\geq 10)$ & 297 & 3 & 1.0 & & \\
\hline \multirow[t]{4}{*}{ Age } & & & & & 8.0 & 0.018 \\
\hline & $<2$ years & 156 & 7 & 4.5 & & \\
\hline & $2-5$ years & 486 & 12 & 2.5 & & \\
\hline & $>5$ years & 396 & 3 & 0.8 & & \\
\hline \multirow[t]{4}{*}{ BCS } & & & & & 0.14 & 0.934 \\
\hline & Poor & 5 & 0 & 0 & & \\
\hline & Medium & 105 & 2 & 1.9 & & \\
\hline & Good & 928 & 20 & 2.2 & & \\
\hline \multicolumn{7}{|l|}{$\begin{array}{l}\text { Pregnancy } \\
\text { status }\end{array}$} \\
\hline & $\begin{array}{l}\text { Non- } \\
\text { pregnant }\end{array}$ & 993 & 22 & 2.2 & & \\
\hline & Pregnant & 45 & 0 & 0 & & \\
\hline \multirow[t]{5}{*}{ Parity } & & & & & 0.94 & 0.816 \\
\hline & $1-2$ & 448 & 11 & 2.5 & & \\
\hline & $3-5$ & 273 & 4 & 1.5 & & \\
\hline & $>5$ & 5 & 0 & 0 & & \\
\hline & $\begin{array}{l}\text { Calves and } \\
\text { heifers }\end{array}$ & 312 & 7 & 2.2 & & \\
\hline \multirow[t]{4}{*}{ Lactation } & & & & & 5.3 & 0.070 \\
\hline & Dry & 68 & 4 & 5.9 & & \\
\hline & Lactating & 659 & 11 & 1.7 & & \\
\hline & $\begin{array}{l}\text { Calves and } \\
\text { heifers }\end{array}$ & 311 & 7 & 2.3 & & \\
\hline
\end{tabular}

However, in multivariable analysis, age and lactation were found to be significantly associated with tuberculin positive reaction (Table 3). 
Table 3: Multivariable logistic regression analysis of risk factors for bovine tuberculin reactors in Adama dairy farms

\begin{tabular}{lccccc}
\hline Variable & Odds Ratio (OR) & Std. Err. & Z-values & p-values & 95\% CI for OR \\
\hline Herd size & 0.31 & 0.23 & -1.56 & 0.118 & $0.07-1.34$ \\
Age & 0.11 & 0.07 & -3.43 & 0.001 & $0.03-0.38$ \\
BCS & 1.35 & 1.03 & 0.39 & 0.695 & $0.30-6.04$ \\
Parity & 0.68 & 0.23 & -1.14 & 0.254 & $0.35-1.32$ \\
Lactation & 0.32 & 0.18 & -2.01 & 0.044 & $0.10-0.97$ \\
Cons & 20.57 & 74.17 & 0.84 & 0.402 & $0.02-24100$ \\
\hline
\end{tabular}

\section{Discussion}

Bovine tuberculosis is known to be endemic in dairy farms of Ethiopia. The present study has shown an apparent individual animal prevalence of $2.1 \%$ in the dairy farms of Adama city. This finding is comparable to a previous report of $2 \%$ in Ethiopia (Gumi et al., 2012) and 2.4\% in Tanzania (Katale et al., 2013). However, it is considerably lower than the previous studies in Ethiopia, viz: 7.9\% (Ameni et al., 2003), 13.5\% (Ameni et al., 2007), 3\% (Tschopp et al., 2010), 30\% (Firdessa et al., 2012), 7.1\% (Nega et al., 2012), 18\% (Mamo et al., 2013), 4.3\% (Romha et al., 2014) and 5.5\% (Dejene et al., 2016). Out of the 206 herds tested, only 15 (7.3\%) had one or more tuberculin positive animals and the number of tuberculin reactors varied widely $(0-55.6 \%)$ between the herds. The present herd-level prevalence was considerably similar range of estimates (12.5 - 56\%) documented in the previous studies done by (Kemal et al., 2019) herd level prevalence of $51.2 \%$; by (Abie et al., 2019) the herd prevalence was $22.4 \%$ in Gondar, Hawassa and Mekelle; by (Dejene et al., 2016) herd prevalence of $46 \%$ in Awash national park and Afar regional state. The herd range variation in the prevalence of tuberculous reactors was thought to be attributed to differences in the herd size of the study animals. As the majority of the herds in the present study were small comprising less than 10 animals, management conditions favoring the spread of bTB, such as overcrowding and poor ventilation, were less likely to have influenced the prevalence of infection. In the present study, age of the animals was found to be significantly associated with positive tuberculin reaction.

In the multivariable analysis of the risk factors considered, lactation status of the animals was another factor found to be significantly associated with tuberculin reactivity although this was not evident in the univariable analy- 
sis. The apparent prevalence was higher among dry cows than lactating cows or calves and heifers. It is difficult to give a plausible biological explanation for this finding and perhaps it might be due to the confounding effect of some other variables unnoticed. In contrast to the present finding, previous studies in Ethiopia that considered lactation status in their analysis did not find significant variation in the prevalence of positive reactors between lactating and non-lactating cattle (Mamo et al., 2013; Romha et al., 2014; Zeru et al., 2014; Dejene et al., 2016). However, the present finding is consistent with Tschopp et al. (2010) and Admasu et al. (2014).

Previous studies in Ethiopia have shown that the native zebu cattle are more resistant to bTB than exotic breeds or their crosses (Vordermeier et al., 2012; Admasu et al., 2014; Sibhat et al., 2017). Consistent to this, the entire tuberculin positive reactors in the current study were Holstein-Friesian X zebu cross breed while none of the local breeds were found reactive. However, the number of local cattle included in the study was too small to compare with the cross breeds. Because the milk yield of cross breed is higher than the local ones, owners prefer to keep the cross breed animals for dairy farms. Therefore, the current evidence is not sufficient to declare breed differences in susceptibility to bTB.

None of the pregnant cows tested in the current study were positive for tuberculin reaction and the entire test positive animals were non-pregnant. However, previous studies have shown lack of significant difference between pregnant and non-pregnant cows (Romha et al., 2014; Zeru et al., 2014). Likewise, no significant association ( $p>0.05)$ was found between parity numbers and positive reaction to tuberculin test and this is consistent with previous studies (Romha et al., 2014; Zeru et al., 2014).

In the present study about $5.6 \%$ of the study animals were reactive for avian Mycobacterium PPD. This is much higher than a previous report of $0.7 \%$ in Ethiopia (Gumi et al., 2012). Reaction bias to $M$. avium PPD could be due to infection with Mycobacterium avium subsp. avium and Mycobacterium avium subsp. paratuberculosis. The latter causes a chronic debilitating disease known as paratuberculosis in cattle, which are most susceptible to infection when they are young. Apart from its economic impact on cattle production, $M$. avium sub spp. paratuberculosis has a zoonotic significance (Radostits et al., 2007). 
In conclusion the present study has shown a very low prevalence of bTB in the dairy farms studied compared to previous reports in the country. As the proportion of cattle affected with bTBin each herd was small, culling of the positive reactors could be a feasible control intervention. Thus owners of the positive herds need to be advised in this regard. Furthermore, the observation of atypical TB with a proportion higher than bTB warrants the need for future studies to focus on Mycobacterium spp. other than $M$. tuberculosis complex, particularly $M$ avium sub spp. paratuberculosis due to its zoonotic and economic importance.

\section{Conflict of interests}

The authors declare that they have no conflict of interests.

\section{Acknowledgements}

The authors would like to thank Aklilu Lemma Institute of Pathobiology and College of Veterinary Medicine and Agriculture of Addis Ababa University and Hawassa University for the financial and technical support obtained during the study. The authors also express special thanks to the owners or managers of the dairy farms included in the study for their cooperation during the study period.

\section{References}

Abie, M, Conlan, A, Berg, S, Ayele, B, Alemu, A and Guta S., 2019. Prevalence of bovine tuberculosis and its associated risk factors in the emerging dairy belts of regional cities in Ethiopia. Prev. Vet. Med., 168: 81-89. doi.org/10.1016/j.prevetmed.2019.04.010

ACAFD, 2016. Adama city Animal and Fisheries Department report. Unpublished report.

Admasu, P., Berihun, W. and Niguse, A., 2014. Prevalence of bovine tuberculosis in dairy cattle of Yeki district, Southern Ethiopia. African J. Basic \& Appl. Sci., 6 (5): 135-140.

Ameni, G., Bonnet, P. and Tibbo, M. 2003. A cross-sectional study of bovine tuberculosis in selected dairy farms in Ethiopia. Int. J. Appl. Res Vet. Med. 1(4):1-8.

Ameni, G., Aseffa, A., Engers, H., Young, D., Gordon, S., Hewinson, G., and Vordermeier, M., 2007. High prevalence and increased severity of pathology of bovine 
tuberculosis in Holsteins compared to Zebu breeds under field cattle husbandry in central Ethiopia. Clin. Vaccine Immunol.14:1356-1361.

Ameni, G., Hewinson, G., Aseffa, A., Young, D. and Vordermeier, M., 2008. Appraisal of interpretation criteria for the comparative intradermal tuberculin test for diagnosis of tuberculosis in cattle in central Ethiopia. Clin. Vaccine Immunol.15 (8):1272-1276.

CSA, 2018. Central Statistical Agency Agricultural Sample Survey Volume II

Dejene, S.W., Heitkönig, I.M.A., Prins, H.H.T., Lemma, F.A., Mekonnen, D.A., Alemu, Z.E., Kelkay, T.Z. and de Boer W.F., 2016. Risk factors for bovine tuberculosis (bTB) in cattle in Ethiopia. PLoS ONE 11(7): e0159083. https://doi.org/10.1371/ journal.pone. 0159083

de Lahunta, A. and Habel, RE., 1986. Teeth - Applied Veterinary Anatomy; USA. W. B. Sounders Company. Philadelphia, PA, pp. 4-16.

Firdessa, R., Tschopp, R., Wubete, A., Sombo, M., Hailu, E., Erenso, G., Kiros, T., Yamuaha, L., Vordermeier, M., Glyn-Hewinson, R., Young, D., Gordon, SV., Sahile, M., Aseffa, A. and Berg, S., 2012. High prevalence of bovine tuberculosis in dairy cattle in Central Ethiopia: Implications for the dairy industry and public health. PLoS ONE 7(12): e52851. doi:10.1371/journal.pone.0052851.

Gumi, B., Schelling, E., Firdessa, R., Erenso, G., Biffa, D., Aseffa, A., Tschopp, R., Yamuah, L., Young, D. and Zinsstag, J., 2012. Low prevalence of bovine tuberculosis in Somali pastoral livestock, southeast Ethiopia. Trop. Anim. Hlth. Prod.,44 (7): 1445-1450. doi: 10.1007/s11250-012-0085-5

Katale, BZ., Mbugi, EV., Karimuribo, ED., Keyyu, JD., Kendall, S., Kibiki, GS., Godfrey-Faussett, P., Michel, AL., Kazwala, RR., van Helden, P. and Matee, MI., 2013. Prevalence and risk factors for infection of bovine tuberculosis in indigenous cattle in the Serengeti ecosystem, Tanzania. BMC Vet. Res., 9:267. doi: 10.1186/17466148-9-267

Kemal, J., Sibhat, B., Abraham, A., Terefe, Y., Tafess, K., Welay, K., Getahun, N. 2019. Bovine tuberculosis in eastern Ethiopia: prevalence, risk factors and its public health importance. BMC Infect Dis., 19: 39. doi: 10.1186/s12879-018-3628-1

Mamo, G., Abebe, F., Worku, Y., Hussein, N., Legesse, M., Tilahun, G., Medhin, G., Bjune, G. and Ameni, G. 2013. Bovine tuberculosis and its associated risk factors in pastoral and agro-pastoral cattle herds of Afar Region, Northeast Ethiopia. J. Vet. Med. Anim. Hlth. 5 (6): 171-179.

Nega, M., Mazengia, H., and Mekonen, G., 2012. Prevalence and zoonotic implications of bovine tuberculosis in Northwest Ethiopia. Int. J. Med. Med. Sci. 2 (9):188-192. 
Nicholson, MJ., and Butterworth, MH., 1986. A guide to condition scoring of zebu cattle; ILCA, Addis Ababa, Ethiopia.

OIE, 2009. Office International des Epizooties (OIE) Terrestrial manual: Bovine Tuberculosis, World Health Organization for Animal Health, Paris, France.

OIE, 2016. Manual of Diagnostic Tests and Vaccines for Terrestrial Animals. Office Internationale des Epizooties (OIE), Paris, France.

Radostits, OM., Leslie, KE., and Fetrow, J., 2001. Herd health: Food Animal Production Medicine, $3^{\text {rd }}$ edition. W.B. Saunders Company, PA, 296.

Radostits, OM., Gay, CC., Hinchcliff, KW., and Constable, PD., 2007. Veterinary Medicine: A textbook of the disease of cattle, horses, sheep, pigs and goats. $10^{\text {th }}$ edition. Elsevier Ltd. London, UK.

Romha, G., Gebreegziabher, GM. and Ameni, G., 2014. Assessment of bovine tuberculosis and its risk factors in cattle and humans, at and around Dilla town, southern Ethiopia. Anim. \& Vet. Sci., 2(4): 94-100.

Sibhat, B., Asmare, K., Demissie, K., Ayelet, G., Mamo, G. and Ameni, G., 2017. Bovine tuberculosis in Ethiopia: A systematic review and meta-analysis. Prev. Vet. Med., 147: 149-157.

Thrusfield, M., 2005. Veterinary Epidemiology, $3^{\text {rd }}$ edition. Pp.182-187. Blackwell Publishing Company. Oxford, UK.

Tschopp, R., Aseffa, A., Schelling, E., Berg, S., Hailu, E., Gadisa, E., Habtamu, M., Argaw, K. and Zinsstag, J., 2010. Bovine tuberculosis at the wildlife-livestockhuman interface in Hamer Woreda, South Omo, Southern Ethiopia. PLoS One. 5(8): e12205, doi: 10.1371/journal.pone.0012205

Vanholder, T., Papen, J.; Bemers R., Vertenten, G. and Berge, A. 2015. Risk factors for subclinical and clinical ketosis and association with production parameters in dairy cows in the Netherlands. J. Dairy Sci.,98(2) 880-888. doi: 10.3168/jds.20148362

Vordermeier, M., Ameni, G., Berg, S., Bishop, R., Robertson, BD., Aseffa, A., Hewinson, RG. and Young, DB., 2012. The influence of cattle breed on susceptibility to bovine tuberculosis in Ethiopia. Comp. Immunol. Microbiol. Infect. Dis., 35: 227- 232.

Zeru, F., Romha, G., Berhe, G., Mamo, G., Sisay, T. and Ameni, G., 2014. Prevalence of bovine tuberculosis and assessment of Cattle owners' awareness on its public health implication in and around Mekelle, Northern Ethiopia. J. Vet. Med. Anim. Hlth. 6(6): 159-167 